Elsevier

HRR 00898

\title{
Techniques for the observation and measurement of red blood cell velocity in vessels of the guinea pig cochlea
}

\author{
Alfred L. Nuttall \\ Kresge Hearing Research Institute, Dept. of Otolaryngology, The University of Michigan, Ann Arbor, U.S.A.
}

(Received 12 November 1986; accepted 26 December 1986)

\begin{abstract}
Fluorescence techniques combined with intravital microscopy provide a powerful approach to the study of cochlear blood microcirculation. In the current study, fluorescein isothiocyanate conjugated to high molecular weight dextrans was added to plasma to enhance the visual contrast of flowing blood in microscopic images from the guinea pig cochlea. Photometric signals, obtained from video pictures of the blood vessels, provided a means to continuously measure red cell velocity by using crosscorrelation algorithms to extract the time delay for moving features of the image. Alternatively, a small amount of fluorescently-labeled red blood cells (RBCs) were added to the vascular volume to serve as natural indicators of whole blood flow. The speed of these cells was measured by video photometric detection of the time required for the cells to pass between two predetermined positions in the television image. RBCs can be made fluorescent by chemical bonding of a fluorochrome to the cell membrane or by internal loading of the cell with an inert fluorochrome. Labeled RBCs provide a means to determine blood velocity in capillaries having extremely poor optical contrast, a situation which is generally the case for relatively thick tissues such as the lateral wall of the membranous labyrinth.
\end{abstract}

Fluorescence; Intravital microscopy; Microcirculation; Red blood cell; Velocity; Cochlea

\section{Introduction}

Measurement of blood flow in the cochlea has been the goal of a number of studies over at least a quarter of a century. Interest in this subject is motivated by known high metabolic demand of cochlear tissues such as the stria vascularis (Chou and Rodgers, 1962; Thalmann et al., 1972) and the potential role that ischemia may have in cochlear injury following noxious insults such as sound (Misrahy et al., 1958; Hawkins, 1971) or ototoxic drugs (Lawrence, 1970). It is also possible that vascular changes may be part of the etiology of Sudden Deafness Syndrome (e.g. Plasse et al., 1980; Millen et al., 1982).

Many techniques have been developed to measure cochlear blood flow and the physiological

Correspondence to: A.L. Nuttall, Kresge Hearing Research Institute, 1301 East Ann Street, The University of Michigan Medical School, Ann Arbor, MI 48109, U.S.A. processes relating to the blood supply. Each has a set of strengths and weaknesses, and none provides a complete knowledge of the relevant parameters of inner ear circulation. Currently three methods dominate the study of cochlear microcirculation: (1) total cochlear blood flow measurements using labeled or unlabeled microspheres (e.g. Angelborg et al., 1977; Hultcrantz, 1979; Prazma et al., 1984); (2) laser Doppler flowmetry (e.g. Miller et al., 1983; Goodwin et al., 1984); and (3) microelectrode oxygen tension determinations (e.g. Misrahy et al., 1958; Maass et al., 1976; Nuttall et al., 1981). Microsphere techniques provide an absolute measure of blood flow in $\mathrm{ml} / \mathrm{min}$ per cochlea. However, for technical reasons, the study of flow dynamics is not practical and the achievement of high accuracy is difficult. Laser Doppler flowmetry is a valuable new method which gives excellent information on blood flux dynamics. For the cochlea, however, the technique provides only information on relative changes in blood flux because of uncertainty about the par- 
ticular tissue volume which is being measured. Oxygen microelectrodes provide good dynamic performance and a very localized measurement, but one which is only indirectly related to blood flow because both oxygen utilization and supply are simultaneous components of the measurement.

One of the oldest methods used to study cochlear microcirculation is the direct visualization of the flowing blood in the vessels of the inner ear (Weille et al., 1954; Seymour, 1954; Perlman and Kimura, 1955). The advantages of the method are (1) the ability to measure the flow velocity of cells (which can lead to determinations of whole blood flow in a vessel or network of vessels if the microhematocrit is also measured; (2) the ability to study the dynamics of microcirculatory changes; (3) the ability to define the exact location of the measurement even to the specific vessel in a capillary bed; and (4) the possibility to observe and discover the morphological and physiological basis of a flow change. The principal disadvantage is possibility of surgical damage during the opening of the cochlea.

The unique capabilities of direct microscopy for the study of cochlear blood flow depend on the implementation of practical quantitative methods for this purpose. Quantitative determinations of cochlear blood cell velocity were first achieved by Perlman and Kimura (1955) by use of tedious and expensive cinematographic methods. That is, blood cell movement was tracked frame to frame in a motion picture film of the flow (see also Lawrence and Clappcr, 1972). Costa and Branemark (1970) later adapted closed circuit television techniques to the study of cochlear microcirculation, opening the possibility of video based methods which are the substance of this report.

Microcirculation physiologists in other organ systems have developed various techniques of quantitative microscopy allowing systemic investigations into basic questions of circulation control, capillary permeability, oxygen delivery, and rheology. In order to accomplish many of these studies, it is necessary to measure red blood cell velocity. Thus, from studies of microcirculation in nonauditory tissues, one can derive a set of techniques and procedures which are suitable for study of cochlear circulation. This report provides the details of methods used recently to measure red blood cell velocity in the guinea pig cochlea (Nuttall, 1986a,b,c, 1987).

\section{Experimental and Discussion}

Measurements of the velocity of red blood cells in the cochlea can be made from a number of different locations in the cochlea and from a number of different blood vessel types at each location. The success in accomplishing the measurement is dependent on the correct choice of animal model, the proper surgical preparation of the animal and cochlea (for normal physiology) and the application of appropriate measurement instrumentation.

\section{Surgical preparation}

Guinca pigs have generally been the animal of choice for microcirculation experiments. This is motivated by the accessibility of the cochlea, its well-known physiology, and the adequate vascular volume of the guinea pig which permits practical manipulations of blood volume, administration of intravenous fluids and sampling of blood for gas analysis. The lack of a stapedial artery, which crosses the basal turn in some rodents, may also be important.

Pigmented guinea pigs are probably the choice of contemporary work on the auditory system (Bock and Steel, 1984). This may be particularly true of vascular studies as the melanocytes have a complex role in the function of the stria vascularis (Meyer zum Gottesberge-Orsulakova, 1986). Pigmentation of the lateral wall could degrade image quality in microscopic images of vessels but this problem is partly overcome for RBC velocity determinations where a complete view of a vessel is not needed and fluorescent methods (described below) reduce the effect of absorption and scattering of light by pigmentation.

Guinea pigs are ancsthetized by administration of diazepam $(5.0 \mathrm{mg} / \mathrm{kg}$ body wt i.p.) followed about $15 \mathrm{~min}$ later by fentanyl $(0.32 \mathrm{mg} / \mathrm{kg}$ body wt i.m.). This anesthesia protocol has proven very reliable for maintaining systemic blood pressure (Brown et al., 1987).

The animals are wrapped in a heating pad which is thermoregulated to control the rectally measured temperature at $38.5^{\circ} \mathrm{C}$. Heart rate is monitored. The ipsilateral common carotid is can- 
nulated to monitor blood pressure. The contralateral external jugular vein is cannulated for intravenous injections. A conventional ventrolateral surgical dissection is carried out exposing the auditory bulla which is then opened over its ventral surface. The tympanic membrane and ossicles can be left intact (depending on experimental goals) as the working distance of the microscope objective is greater than $10 \mathrm{~mm}$.

The head is securely fastened into a manipulator which is heated in order to prevent conductive cooling of the head. A thermocouple is placed in contact with the bony wall of the cochlea and temperature of the cochlea is continuously monitored and controlled by a heat lamp near the head.

The local concentration of oxygen and carbon dioxide near the cochlea is controlled by blowing an appropriate gas mixture into the bulla. Oxygen concentration of the gas in the bulla is reduced from normal atmospheric levels to between $2 \%$ and $8 \%$ and carbon dioxide concentration is raised to between $4 \%$ and $5 \%$. This is done to avoid alteration of tissue gas concentrations once the cochlear wall is opened. Svensjo et al. (1977) have shown that local gas concentration can influence blood flow in the hamster cheek pouch. $\mathrm{O}_{2}$ and $\mathrm{CO}_{2}$ concentrations are monitored using a capillary sampling tube positioned near the cochlea which draws gas from the open bulla (by suction pump) at $40 \mathrm{ml} / \mathrm{min}$ and delivers it to oxygen and carbon dioxide gas analyzers. $\mathrm{Gas}\left(95 \% \mathrm{~N}_{2}, 5 \% \mathrm{CO}_{2}\right)$ is blown (approximately $400 \mathrm{ml} / \mathrm{min}$ ) towards the open bulla from a $1 / 4$ inch (ID) tube placed within $1 \mathrm{~cm}$ of the bulla and directed toward it. The gas is humidified and heated before it is delivered to the bulla.

Two successful ways of opening the cochlea are either by scraping the otic capsule until the thinned spot cracks and the bone chips can be removed with small wire hooks or by creating a window opening over the spiral ligament and stria vascularis after scoring a rectangle of scratch marks into the bone. The latter is preferrable because of its convenience. Fig. 1 shows a schematic drawing of the cochlea and the position of an opening over the third turn membranous labyrinth.

\section{Intravital microscopy}

The microscope used in these studies was as-

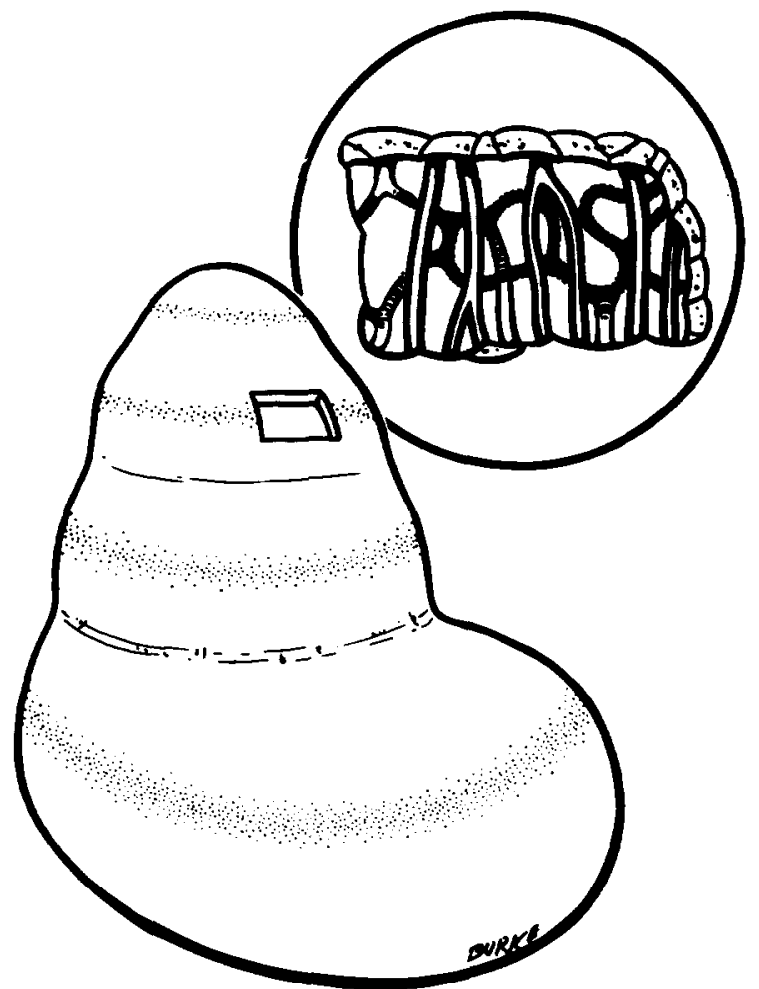

Fig. 1. An illustration of the guinea pig cochlea showing the approximate size and location of a window opening over the membranous labyrinth of the third turn. The inset schematically shows the patterns of spiral ligament vessels overlying decper stria vascularis vesscls.

sembled from components produced by several manufacturers. The main components are a Leitz vertical illuminator unit and a Leitz trinocular head. The vertical illuminator allows fluorescence microscopy and it is of the infinity-corrected type. Infinity-corrected optics permit the straight-forward implementation of telescopic microscopy principles (Wayland and Frasher, 1973; Slaaf et al., 1982; Nuttall, 1986b). Fig. 2 illustrates the construction of the microscope which uses Olympus long-working-distance infinity-corrected lenses (ULWD).

The microscope components are carried on a sturdy framework permitting convenient placement of the animal preparation, manipulation of the microscope position in the $x-y$ plane, and easy interchange of the compound microscope for a dissection microscope in order to view and attend to the specimen preparation at low magnification. 


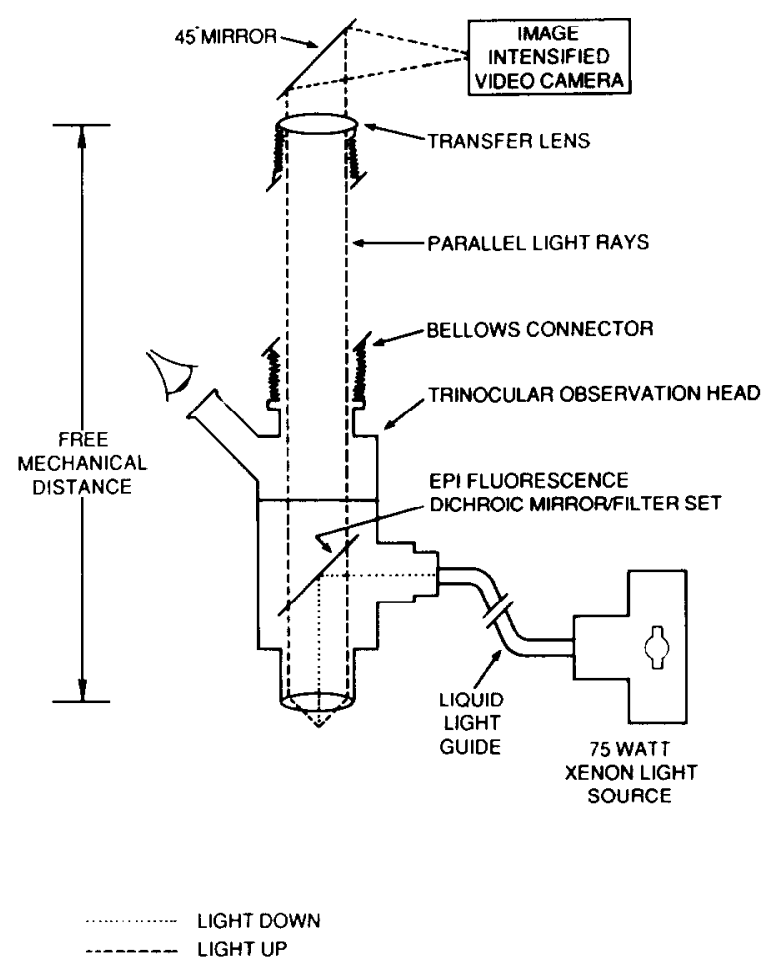

Fig. 2. Schematic drawing of the intravital microscope used for cochlear microcirculation studies. Epifluorescence microscopy is achieved by using a vertical illumination system. An infinity-corrected long-working-distance microscope objective is used with a transfer lens in an implementation of telescopic microscopy principles. This permits the free mechanical distance to be conveniently changed without affecting the image focus of magnification at the video camera.

Most experiments on blood cell velocity are accomplished using an Olympus $20 \times$ ULWD objective having a working distance of $11 \mathrm{~mm}$. Parallel light rays from the back aperture of the lens are intercepted by a $63 \mathrm{~mm}$ diameter (focal length $400 \mathrm{~mm}$ ) acromat doublet (Melles Griot LAO 333) which acts as a transfer lens and focuses the image on the sensor of a silicon intensified target (SIT) video camera (Dage MTI model 66). An advantage of telescopic microscopy is the ability to vary the free mechanical distance (between the objective and the transfer lens) without altering the magnification or focus at the image plane. An additional advantage is that the bulk and weight of the camera or recording systems are physically removed from the microscope head near the animal preparation. In the current implemen- tation of the method, the free mechanical distance is approximately $25 \mathrm{~cm}$.

Iight is supplied to the vertical illuminator from a 75 watt Zenon source through a 5 foot long, $3 \mathrm{~mm}$ diameter, liquid light-guide. For fluorescence, the filter set consists of an excitation filter (band pass $450-490 \mathrm{~nm}$ ), a dichroic mirror (reflection short pass $510 \mathrm{~nm}$ ), and a suppression filter (long pass $510 \mathrm{~nm}$ ). This is the fluorescence filter set of a typical fluorescence microscope configured for fluorescein isothiocyanate (FITC). Resulting fluorescence from fluorescein labeled dextran or red blood cells is readily visible to the eye but it cannot be imaged by a conventional vidicon or newvicon video camera. One stage of image intensification is sufficient to bring the signal to uscful lcvels without excessive noise. The SIT video camera is a compromise choice of sensitivity, resistance to blooming and lag, resolution, stability, and cost.

\section{Fluorescent labeling}

Fluorescence techniques are an important part of these procedures for measuring red cell velocity in the cochlea because they improve the visual contrast of relevant structures in the images from the living inner ear. Biological tissues in their living state generally have very low contrast under bright-field microscopic conditions. Contrast enhancement procedures for unstained tissue are often based on polarized transmitted light techniques which are not feasible for the intact cochlea. Fluorescent structures in a tissue act as selfluminous objects greatly improving contrast.

FITC-dextran labeling of plasma FITC conjugated to dextrans of various molecular weights have often been used to study the permeability of microvessels (e.g. Olsson et al., 1975). In the current rcd cell velocity determinations, the substance acts as a contrast medium for blood. FITC-dextran (Sigma) is administered intravenously to the guinea pig at a dose of $50 \mathrm{mg} / \mathrm{ml}$ of physiological saline infused slowly over a $15 \mathrm{~min}$ period. The molecular weight of the dextran has a mean value of $150 \mathrm{kDa}$ and this size molecule does not leak significantly from the vasculature (Olssen et al., 1975). Administered slowly, it also does not create an oncotic imbalance in plasma and total volume 


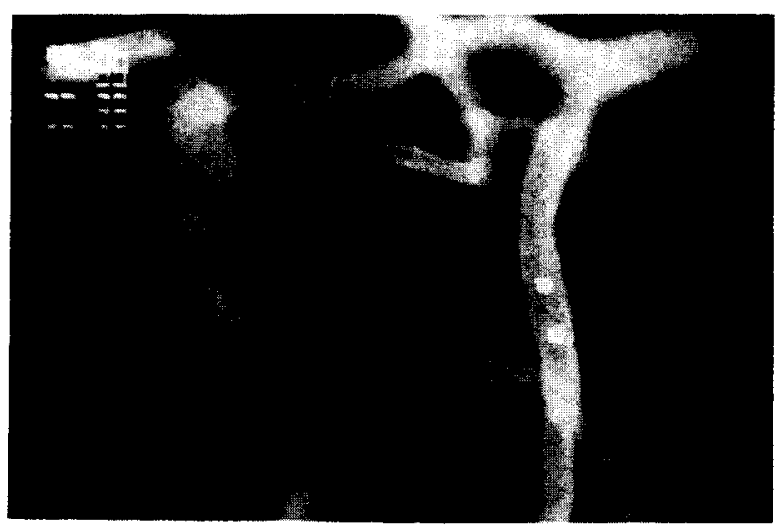

Fig. 3. A photograph of the face of a video monitor showing blood vessels in the lateral wall of the guinea pig cochlear third turn. The vessels are made fluorescent by a constant medium (FITC-dextran) which has been intravenously administered. The numbers in the upper left hand corner are arbitrarily generated time and frame count values. The small white squares in the center right of the figure are photometric analysis windows. Four separate video frames of moving blood were averaged to obtain this image.

administered is less than $2 \%$ to $3 \%$ of the vascular volume for a $400 \mathrm{~g}$ guinea pig.

Fig. 3 is a photograph taken of the face of the television monitor showing capillaries of the guinea pig cochlear third turn lateral wall. The lumina of these vessels are made visible by the fluorescence of FITC-dextran mixed with plasma. Four random video frames (from a 1 s long frame sequence) were averaged to smooth the image of the vessel walls.

Fluorescent labeling of red blood cells RBCs may be labeled by fluorescent dyes in order to improve visual contrast. They then can serve as naturally flowing indicators giving information on the instantaneous and mean velocity of the total $R B C$ population or other parameters of the microcirculation. (Note that if all flowing RBCs are labeled, one would achieve the effective inverse of the situation in the section immediately above where fluorescent light eminates from plasma and RBCs extinguish the fluorescence in a vessel lumen.) It is generally advantageous to use only a small number of labeled cells. However, this increases the time required to determine the population mean velocity. Some of the factors which influence the choice of labeled fraction level are discussed in the next section. In order to label the cells, two procedures have been used: (1) chemical bonding of a fluorochrome to the exterior surface of the erythrocyte membrane and (2) internal loading of an indicator dye inside the erythrocyte.

For either procedure, first approximately $2 \mathrm{cc}$ of whole blood is obtained by heart puncture into a syringe containing EDTA $(44 \mathrm{mg} / \mathrm{ml})$ from a guinea pig weight-matched to the experimental animal.

For external labeling, a modification of the method of Tangelder (Pers. Commun.) is used. Erythrocytes are separated and washed three times in isotonic saline or phosphate buffered saline. To the washed, packed cells are added $310 \mathrm{mM}$ dextrose in saline, $280 \mathrm{mOsm} \mathrm{NaH}{ }_{2} \mathrm{PO}_{4}$ and FITC in 230 mOsm $\mathrm{Na}_{2} \mathrm{HPO}_{4}$ (pH 9.0). Afther thorough mixing, additional $230 \mathrm{mOsm} \mathrm{Na}_{2} \mathrm{HPO}_{4}$ is added and $\mathrm{pH}$ adjusted to $7.9-8.0$ with $1 \mathrm{~N} \mathrm{NaOH}$ if necessary. The suspension is incubated at room temperature for about $2 \mathrm{~h}$, then the labeled cells are washed at least 3-4 times in saline to remove excess dye. Washed, packed cells are suspended in saline for a final hematocrit of about $60 \%$.

Fluorescent dye can also be entrapped inside RBCs by resealing the cell ghosts produced by a modification of a pre-swell loading procedure (Rechsteiner, 1975; Tsang et al., 1985). Washed, packed erythrocytes are suspended in fourfold their volume of dilute phosphate buffered saline with $5 \mathrm{mM}$ dextrose, $5 \mathrm{mM}$ inosine, $4 \mathrm{mM} \mathrm{MgSO}_{4}$ (160 mOsm, $\mathrm{pH} \mathrm{7.4)} \mathrm{for} 5 \mathrm{~min}$, centrifuged and the swelling operation repeated. Lysis is induced by adding to the packed cells $3 / 4$ their volume of $8 \mathrm{mg} / \mathrm{ml} \mathrm{FITC-BSA} \mathrm{(Sigma)} \mathrm{or} 1 \mathrm{mg} / \mathrm{ml}$ calcein (Sigma) in $100 \mathrm{mOsm}$ phosphate buffered saline. After a 2-5 min equilibration period, cell membranes are resealed by addition of sufficient 1.54 $\mathrm{M} \mathrm{NaCl}$ to restore isotonicity. The suspension is incubated at $40^{\circ} \mathrm{C}$ for about $60 \mathrm{~min}$ and resealed cells are washed 4-5 times in phosphate buffered saline. Final hematocrit is adjusted to about $60 \%$. Calcein is a brightly fluorescent indicator for $\mathrm{Ca}^{2+}$ (Wallach et al., 1959) concentration and commonly used for fluorometric determinations (Kepner and Hercules, 1963). Here it acts only to label the cytoplasm of RBCs (see Conner and Huang, 1985, for a similar application), and it has 


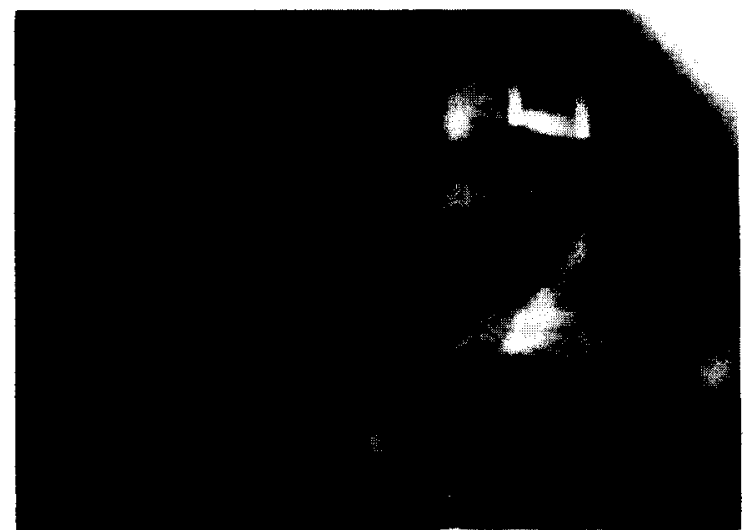

Fig. 4. A photograph of the face of a video monitor showing a network of third turn cochlear vessels. The lumina of these vessels are slightly fluorescent from FITC-dextran and a small number of fluorescent RBCs are located at various positions in the network. For example, one labeled RBC is located between the two white rectangular boxes which are the analysis windows of the photometric analyzer.

previously been used for this purpose (Ihler, Pers. Commun.).

Fig. 4 is a photograph of the face of the television monitor showing individually labeled RBCs distributed in a network of capillaries of the guinea pig third turn lateral wall. The noisy character of this photo is caused by the high video intensifier gain needed to visualize the faint fluorescence of the lumina of capillaries (because of the low concentration of FI'TC-dextran).

\section{Measuring red blood cell velocity}

Speed measurement A number of techniques have been devised to quantify $\mathrm{RBC}$ velocity in video images of flowing blood. One of the earliest was the flying spot method (see Tyml and Ellis, 1982, for a recent application) which was used by Costa and Branemark (1970) for their study of cochlear blood flow. The flying spot in modern usage is generally an electrically generated spot of light superimposed on the video image which moves at user setable speeds along a straight line. The speed of the spot is matched to the movement speed of the blood by the observer. An important disadvantage of the method is the need for operator judgment about the matching of speed. An alternative approach to measure red cell speed was taken in the current work making use of commercially available hardware to selectively extract information from video images. The video photometric analyzer [Instruments for Physiology and Medicine (IPM) model 204] is one such instrument which derives two continuous analog signals proportional to the average video intensity level in two areas (windows) of the image ("dual slit photometry"). The physical area of the windows and their location are user setable.

The two analog signals may then be processed by any number of techniques to derive the time required for a feature to pass between the two window locations in the image. Determining the effective distance between the windows (projected into the object plane) allows calculation of velocity. This electronic timing of the passage of RBCs was used by Nuttall (1987) to measure velocity in vessels of the guinea pig lateral wall.

The advantages of measurements from a single RBC are many. Sarelius and Duling (1982) discuss methods which derive microhematocrit and capillary bed transit time. The exact choice of labeled fraction volume depends on the purpose of the experiment, the size of the blood vessels, and velocity of RBCs within the vessel (Sweeney and Sarelius, 1985).

For unambiguous determination of velocity using the video photometric analyzer, it is requisite that only one cell appear between the analysis windows at a time. If more than one cell were between the windows, crosscorrelation techniques could be used.

Time delay determined by crosscorrelation From one of the first successful applications of "dual slit" photometry (Wayland and Johnson, 1967) several improvements evolved for automatic online velocity tracking (e.g. Intaglietta et al., 1970; Intaglietla and Tompkins, 1972a; Tompkins et al., 1974; Slaaf et al., 1981). One branch of this development was the implementation of crosscorrelation to video signals (Intaglietta and Tompkins, $1972 \mathrm{~b}$ ) and commercial instrumentation became available for this purpose (IPM velocity tracking correlator, model 102).

Among the advantages of the video based methodology are (1) the ease with which various portions of the image may he analyzed by elec- 
Ironic positioning of analysis windows in the image; and (2) the pattern of blood flow may be video taped for off-line analysis allowing a particular time sequence of flow velocity to be repeatedly played back for sequential analysis of many blood vessels. The method is limited however by frequency considerations of the television system, most particularly the frame rate of $60 \mathrm{~Hz}$. In practice, this limits determinations of red cell velocity to between 0.1 and $1.0 \mathrm{~mm} / \mathrm{s}$.

Fig. 5 shows a block diagram of the velocity measurement system, consisting of a video tape recorder (Sony $5200 \mathrm{U}$-matic) which records the signal from the SIT camera after insertion of time and frame count information into the picture (IPM model 710 video time code generator). This allows a unique identification of each frame. The video signal is passed to a video dual-photometric analyzer (IPM model 204) from which two analog signals are derived representing the average intensity of the video picture within analysis windows (of user defined size). The signals are given to an analog crosscorrelator (IPM model 102) which computes and displays a 64 point crosscorrelation function and determines the velocity (time delay) to maximum correlation according to the method of Tompkins et al. (1974). Computed velocity can be recorded on a strip chart recorder.

The use of automatic (continuous) velocity measurement in the cochlea is greatly enhanced by the fluorescence techniques described earlier. Ordinarily velocity measurements are achieved

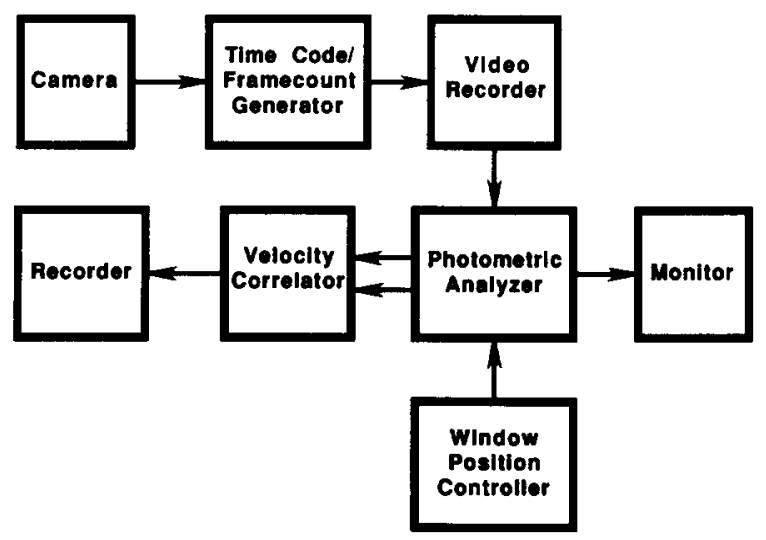

Fig. 5. Block diagram of the video system for analysis of red cell velocity. only from relatively high quality (i.e. high contrast) microscopic images of blood flow. These are generally obtained from thin tissues with transmitted light conditions. Images of cochlear circulation are from comparatively thick tissue which cannot be properly transilluminated. Fluorescence of plasma or red cells improves the contrast of the relevant structures (flowing blood) thereby improving the signal-to-noise ratio of the image.

The decision to use FITC-dextran to label plasma or label RBCs is a compromise of several factors. When labeled plasma is used, all information contained in the video intensity structure of the flowing column of blood is available to the correlation. In theory this enhances the correlation and allows more accuracy for determination of charges in velocity. For example, averaging time constants of the correlation can be well below $5 \mathrm{~s}$, allowing observation of vasomotion related velocity changes which typically have peak power spectra around $0.16 \mathrm{~Hz}$ (Meyer and Intaglietta, 1986). In practice, the lag characteristic (residual image) of image intensified cameras adds to diminished contrast in microscopic views of capillaries in thick tissues and the generally low velocity of blood capillaries of the lateral wall (Nuttall, 1987) are often below the operating range of the instrument.

The use of labeled RBCs also improves image contrast and crosscorrelation may also be used to extract time delay information. In order to accomplish this, the volume fraction of labeled cells must be greater than that discussed above for tracking the speed of individual cells. Here the objective is to provide enough continuous signal so that the averaging time of the correlation is reasonably short (under $1 \mathrm{~min}$ ). More than $1 \mathrm{cc}$ of labeled blood (given i.v.) may be required for this and care must be exercised not to influence the total blood hematocrit leading to viscosity related blood flow changes in the cochlea (Hultcrantz and Nuttall, 1986).

\section{Acknowledgments}

This work was supported by Public Health Service NIH program project (NS-05785) and NIH individual grant (NS-11731). Fentanyl citrate, for animal anesthesia, was a gift from the Jannsen 
Pharmaceutical Company. The author wishes to express his gratitude to Drs. G.M. Ihler, I. Sarelius and G.-J. Tangelder for sharing their expertise and experience to help develop the red blood cell labeling techniques. The author also appreciates the following: microscope design suggestions and its construction by instrument maker Franz Weiser; technical support from J. Nadine Brown and Michelle Griffiths; and engineering support from Robert I. Masta.

\section{References}

Angelborg, C., Hultcrantz, E. and Agerup, B. (1977) The cochlear blood flow. Acta Oto-Laryngol. 83, 92-97.

Bock, G.R. and Steel, K.P. (1984) Use of albino animals for auditory research. Hear. Res. 13, 201-202.

Brown, J.N., Thorne, P.R. and Nuttall, A.L. (1987) Blood pressure in the awake and anesthetized guinea pig. In preparation.

Chou, J.T.-Y. and Rodgers, K. (1962) Respiration of tissues lining the mammalian membranous labyrinth. J. Laryngol. Otol. 76, 341-351.

Conner, J. and Huang, L. (1985) Efficient cytoplasmic delivery of a fluorescent dye by $\mathrm{pH}$-sensitive immunoliposomes. $\mathrm{J}$. Cell Biol. 101, 582-589.

Costa, O. and Branemark, P.I. (1970) Vital microscopic evaluation of the microvessels of the cochlea. Adv. Microcir. 3, 96-107.

Goodwin, P.C., Miller, J.M., Dengerink, H.A., Wright, J.W. and Axelsson, A. (1984) The laser Doppler. Acta OtoLaryngol. 98, 403-412.

Hawkins, J.E. (1971) The role of vasoconstriction in noise-induced hearing loss. Ann. Otol. 80, 903-913.

Hultcrantz, E. (1979) The effect of noise on cochlear blood flow in the conscious rabbit. Acta Physiol. Scand. 106, $29-37$.

Hultcrantz, E. and Nuttall, A.L. (1986) Effect of hemodilution on cochlear blood flow. Am. J. Otolaryngol. (in press).

Intaglietta, M. and Tompkins, W.R. (1972a) On-line measurement of microvascular dimensions by television microscopy. J. Appl. Physiol. 32, 546-551.

Intaglietta, M. and Tompkins, W.R. (1972b) On-line microvascular blood cell flow velocity measurement by simplified correlation technique. Microvasc. Res. 4, 217-220.

Intaglietta, M., Tompkins, W.R. and Richardson, D.R. (1970) Velocity measurements in the microvasculature of the cat omentum by on-line method. Microvasc. Res. 2, 462473.

Kepner, D.L. and Hercules, S.M. (1963) Fluorometric determination of calcium in blood serum. Anal. Chem. 35 , 1238.

Lawrence, M. (1970) Circulation in the capillaries of the basilar membrane. Laryngoscope 80, 1364-1375

Lawrence, M. and Clapper, M.P. (1972) Analysis of flow pattern in vas spirale. Acta Oto-Laryngol. 73, 94-103.

Maass, B., Baumgartl, H. and Lubbers, D.W. (1976) Lokale
$\mathrm{pO}_{2}$ and $\mathrm{pH}_{2}$ Messungen mit Nadelelektroden zum Studium der Sauerstoffuersorgung und Mikrozirkulation des Innenohres. Arch. Otol Rhinol. Laryngol. 214, 109-124.

Meyer, J.U. and Intaglietta, M. (1986) Measurement of the dynamics of arteriolar diameter. Ann. Biomed. Eng. 14, 109-117.

Meyer zum Gottesberge-Orsulakova, A. (1986) Melanin in the inner ear: Micromorphological and microanalytical investigations. Acta Histochem. Suppl. Band 32, 245-253.

Millen, S.J., Toohill, R.J. and Lehman, R.H. (1982) Sudden sensorineural hearing loss: Operative complication in nonotologic surgery. Laryngoscope 92, 613-617.

Miller, J.M., Marks, N.J. and Goodwin, P.C. (1983) Laser Doppler measurements of cochlear blood flow. Hear. Res. 11, 385-394.

Misrahy, G.A., Hildreth, K.M., Shinabarger, E.W., Clark, L.C. and Rice, E.A. (1958) Endolymphatic oxygen tension in the cochlea of the guinea pig. J. Acoust. Soc. Am. 30, 247-250.

Nuttall, A.L. (1986a) Distribution of red blood cell flow velocities in capillaries of the guinea pig cochlea. Abstr. 23rd Workshop Inner Ear Biol. Berlin, GDR.

Nuttall, A.L. (1986b) Intravital microscopy for measurement of blood cell velocities in the cochlea. Abstr. Assoc. Res. Otolaryngol. 9th Midwinter Meet. Clearwater Beach, FL.

Nuttall, A.L. (1986c) Blood cell velocity measurements from capillaries of the guinea pig inner ear. Int. J. Microcircul. Clin. Exp. 5, 270.

Nuttall, A.L. (1987) Velocity of red blood cell flow in capillaries of the guinea pig cochlea. Hear. Res. 27, 121-127.

Nuttall, A.L., Hultcrantz, E. and Lawrence, M. (1981) Does loud sound influence the intracochlear oxygen tension? Hear. Res. 5, 285-293.

Olsson, Y., Svensjo, E., Arfors, K.-E. and Hultstrom, D. (1975) Fluorescein labeled dextrans as tracers for vascular perneability studies in the nervous system. Acta Neuropathol. 33, 45-50.

Perlman, H.B. and Kimura, R.S. (1955) Observations of the living blood vessels of the cochlea. Ann. Otol. 64 , $1176-1192$.

Plasse, H.M., Spencer, F.C., Mittleman, M. and Frost, J.O. (1980) Unilateral sudden loss of hearing, an unusual complication of cardiac operation. J. Thorac. Cardiovasc. Surg. $79,822-826$.

Prazma, J., Vance, S.G. and Rodgers, G. (1984) Measurement of cochlear blood flow: New technique. Ilear. Res. 14, 21-28.

Rechsteiner, M.C. (1975) Uptake of proteins by red blood cells. Exp. Cell Res. 93, 487-492.

Sarelius, I.H. and Duling, B.R. (1982) Direct measurement of microvessel hematocrit, red cell flux, velocity, and transit time. Am. J. Physiol. 243, H1018-H1026.

Seymour, J.C. (1954) Observations on the circulation in the cochlea. J. Laryngol. Otol. 68, 689-711.

Slaaf, D.W., Alewijnse, R. and Wayland, H. (1982) Use of telescopic imaging in intravital microscopy: A simple solution for conventional microscopes. Int. J. Microcirc. Clin. Exp. 1, 121-134.

Slaaf, D.W., Jeurens, T.J.M., Tangelder, G.-J., Reneman, R.S. 
and Arts, T. (1981) Computer analysis of the bi-directional optical (BDO-) system for on-line red cell velocity measurements. Bibl. Anat. 20, 48-52.

Svensjo, E., Tuma, R.F. and Arfors, K.-E. (1977) Comparison of arteriolar blood flow in the hamster cheek pouch at two different oxygen tensions. Acta Physical. Scand. 100, 404-411.

Sweeney, T.E. and Sarelius, I.H. (1985) Use of flow cytometry to extend and improve in-vivo determinations of microvessel hematocrit and cell flux. Microvasc. Res. 31, 184-196.

Thalmann, R., Miyoshi, T. and Thalmann, I. (1972) The influence of ischemia upon the energy reserves of inner ear tissues. Laryngoscope 82, 2249-2272.

Tompkins, W.R., Monti, R. and Intaglietta, M. (1974) Velocity measurement by self-tracking correlator. Rev. Scient. Instr. $45,647-649$.

Tsang, H.C., Granger, H.J. and Ihler, G.M. (1985) Visualization of fluorescent erythrocytes in the microcirculation. Exp. Hematol. 13, 811-816.

Tyml, K. and Ellis, C.G. (1982) Evaluation of the flying spot technique as a television method for measuring red cell velocity in microvessels. Int. J. Microcirc. Clin. Exp. 1, 145-155.

Wallach, D.F.H., Surgenor, D.M., Soderburg, J. and Selano, E. (1959) Preparation and properties of 3,6-dihydroxy-2,4bis $\{N, N$-di-(carboxymethyl)-aminomethyl $\}$ fluoran. Utilization for the ultramicrodetermination of calcium. Anal. Chem. 31, 456-460.

Wayland, H. and Frasher, W.G. (1973) Intravital microscopy on the basis of telescopic principles: Design and application of an intravital microscope for microvascular and neurophysiological studies. In: Modern Techniques in Physiological Sciences, pp. 125-135. Editors: Gross, Kaufmann and Wetterer. Academic Press, London.

Wayland, H. and Johnson, P.C. (1967) Erythrocyte velocity measurement in microvessels by two-slit photometric method. J. Appl. Physiol. 232, 333-337.

Weille, F.L., Gargano, S.R., Pfister, R., Martinez, D. and Irwin, J.W. (1954) Circulation of the spiral ligament and stria vascularis of living guinea pig. Arch. Otolaryngol. 59, 731-738. 